42

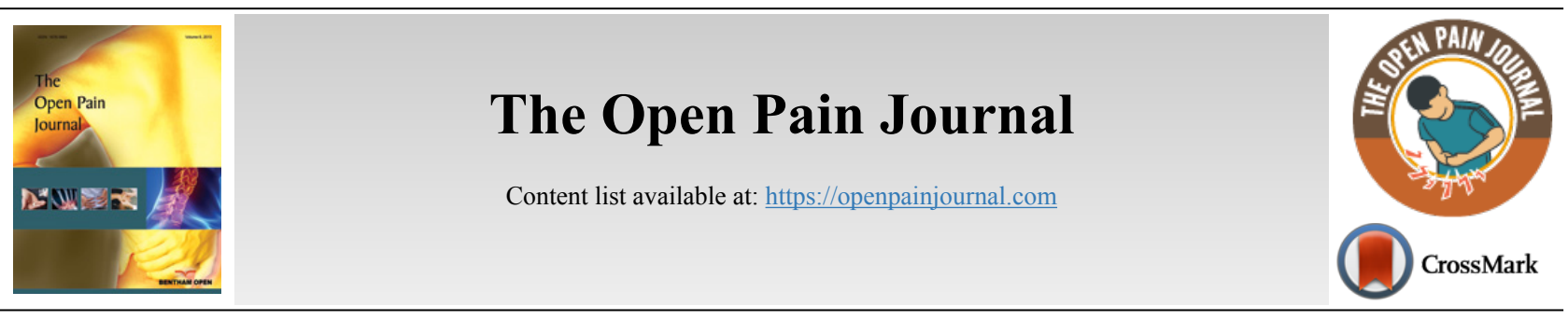

CLINICAL TRIAL STUDY

\title{
Effects of Dexamethasone on Post-dural Puncture Headache in Patients Undergoing Orthopedic Surgery
}

Hadis Barkhori ${ }^{1}$, Farhad Arefi ${ }^{2}$, Kiavash Hushmandi ${ }^{3}$, Salman Daneshi ${ }^{4}$, Jafar Salehi ${ }^{5, *}$, Hamideh Barkhori ${ }^{6}$, Hamid Rafee $^{7}$, Mehdi Raei ${ }^{8}$ and Leila Karimi ${ }^{9}$

${ }^{1}$ School of Medicine, Jiroft University of Medical Sciences, Jiroft, Iran

${ }^{2}$ Department of Nursing, School of Nursing, Jiroft University of Medical Sciences, Jiroft, Iran

${ }^{3}$ Department of Food Hygiene and Quality Control, Division of Epidemiology \& Zoonoses, Faculty of Veterinary Medicine, University of Tehran, Tehran, Iran

${ }^{4}$ Department of Public Health, School of Health, Jiroft University of Medical Sciences, Jiroft, Iran

${ }^{5}$ Department of Anesthesiology, School of Medicine, Kerman University of Medical Sciences, Kerman, Iran

${ }^{6}$ Imam Khomeini Hospital, Jiroft University of Medical Sciences, Jiroft, Iran

${ }^{7}$ Research Center of Prevention and Epidemiology of Non-Communicable Disease, Shahid Sadoughi University of Medical Sciences, Yazd, Iran

${ }^{8}$ Health Research Center, Life Style Institute, Baqiyatallah University of Medical Sciences, Tehran, Iran

${ }^{9}$ Behavioral Sciences Research Center, Life Style Institute, Nursing Faculty, Baqiyatallah University of Medical Sciences, Tehran, Iran

\section{Abstract: \\ Background:}

The effect of Dexamethasone on Post-Dural Puncture Headache (PDPH) after spinal anesthesia has not been well elucidated. The aim of the current study was to evaluate the effect of prophylactic intravenous dexamethasone on the incidence and severity of PDPH in patients undergoing orthopedic surgery.

\section{Methods:}

This randomized, double-blind, placebo-controlled trial was carried out in patients undergoing orthopedic surgery. The subjects were randomly divided into a placebo $(n=140)$ and a dexamethasone $(n=140)$ group. During the surgery, the control group participants were injected 2 cc of distilled water, and the dexamethasone group participants were injected $2 \mathrm{cc}(8 \mathrm{mg})$ of dexamethasone as an infusion in the veins. The incidences of PDPH on the first, third and seventh postoperative days were studied. Data were analyzed using SPSS version 22.

\section{Results:}

A total of 280 patients with a mean age of $32.7 \pm 11.0$ years were studied. The incidence of PDPH on the first day of post-operative period was lower in the dexamethasone group than the control group $(21$ vs. 34, $\mathrm{P}<0.05)$. This difference was disappeared on days 3 and 7 . Nausea or vomiting occurred less in the dexamethasone group $(9$ vs. $26, \mathrm{P}<0.05)$. However, no statistically significant association was found between study groups and the incidence of back pain $(\mathrm{P}>0.05)$.

\section{Conclusion:}

Although the frequency of PDPH was less in patients receiving dexamethasone, the incidence increased days after the operation and reached the level of the placebo group. We do not recommend prophylactic intravenous dexamethasone for the prevention of PDPH.

Keywords: Dexamethasone, Post-Dural puncture headache, Anesthesia, Spinal, Orthopedic surgery, Back pain.

\begin{tabular}{|l|l|l|l|}
\hline Article History & Received: July 15, 2020 & Revised: August 24, 2020 & Accepted: September 08, 2020 \\
\hline
\end{tabular}

\section{INTRODUCTION}

Spinal anesthesia is one of the common methods used in

* Address correspondence to this author at the Department of Anesthesiology, School of Medicine, Kerman University of Medical Sciences, Kerman, Iran; Tel: +989197615525; E-mail: Dr.jsalehi@gmail.com

Obstetrics and gynecology surgeries, urologic surgeries, orthopedic surgeries, etc. Given the facility existing inspinal anesthesia, it is considered as one of the most commonly used nerve blocks. By definition, spinal anesthesia is a form of regional anesthesia involving the injection of a local anesthetic into the subarachnoid space [1]. The complications of this method include neurological complications, low blood pressure, Bradycardia and Asystole, Post-Dural-Puncture 
Headache, nausea, urinary retention, back pain, and red reduced ventilation [2]. Post-Dural-Puncture Headache (PDPH) that is considered as the most important dilatory complication, was first reported in 1899 [3]. The most significant symptom of PDPH is it is positional; it tends to aggravate by standing or sitting, and it is relieved relatively or completely by lying down. The headache is located in the frontal area, occipital area, or both; it is described as either vague or beating. The risk factors affecting the incidence of post-spinal anesthesia headache include age, femininity, and previous headache history $[2,4]$. The surgeon's lack of enough experience is also mentioned as one of the newly recognized risk factors of PDPH; the surgeon generally needs to perform the operation 90 times so that he will be competent enough to perform such operations [5]. In the previous studies, the incidence rate of post-spinal anesthesia headache has been reported to be 11-66 percent [6]. Another cause of post-spinal anesthesia headache, just like other common headaches such as migraine, is the infection and Meningismus arising from taking drugs. Its severity ranges from minor to very severe where the individual cannot perform any activities [7]. Moreover, a headache can last from one day to months; but it is usually relieved up to three days, and in 75 percent of the cases, it is completely relieved up to one week [8]. The common preventive methods include using drinks, using small needles, and special needles so that the tip of the needle is parallel to the Dura mater fibers, not vertical to them [9]. The International Headache Society has introduced some diagnostic criteria for diagnosing PDPH [10]. Applying these criteria for distinguishing PDPH from other headaches such as migraine has been proved useful. PDPH treatment is different in different treatment centers. Although intravenous caffeine has been introduced to be ineffective in some studies, most of the doctors still prescribe intravenous caffeine and rest [11].

Dexamethasone is one of the strongest steroid drugs from the industrial glucocorticoid category that is recognized as an anti-inflammatory drug weakening the immune system [12].

The effects of hydrocortisone in the treatment of postpuncture headaches have been investigated in several studies $[13,14]$. The effects of dexamethasone have also been studied. However, due to the contradictory results of these studies [15, 16] and on the other hand, the availability and ease of administration and low cost of using dexamethasone in the treatment PDPH and also other studies evaluate the effect of Dxamethazone on PDPH in pregnant women after caesarian section and as far as we know, no such study has been performed on orthopedic patients so, we decided to perform this study, therefore, the present research aims at studying the effect of intravenous Dexamethasone on Post-Dural-Puncture Headache (PDPH) in orthopedic patients of Jiroft Imam Khomeini Hospital from 2015 to 2016.

\section{METHODS}

The present study is a double-blind clinical trial. The statistical population of the present study includes all the patients referring to Jiroft Imam Khomeini Hospital, who underwent elective orthopedic surgery; 280 patients were selected using convenience sampling. The following patients were included in the present study: patients with informed consent; patients with no history of migraine, convulsion, and headache-related disease; patients with no underlying diseases; and patients who had not received narcotic drugs and sedatives. The patients with a history of migraine, convulsion, and headache-related disease as well as patients suffering from a special disease or those who had taken narcotic drugs and sedatives, were excluded from the present study. The patients were placed into two groups: the control group (using placebo), and the dexamethasone group (taking Dexamethasone). All the participants of the present study laid supine on the bed in the same conditions and Marcaine anesthetic was injected using spinal needle No.24 in the lumbar area lower than the L2 vertebrae and applying the median method in subarachnoid space. Then, during the surgery, the control group participants were injected $2 \mathrm{cc}$ of distilled water, and the dexamethasone group participants were injected 2cc (8mg) of Dexamethasone as an infusion in the veins. Then the patients were monitored during the operation, in the recovery room, and during their hospital stay with respect to headache. The headache severities of the patients studied were recorded in specific times: 24 hours after the surgery, three days after the surgery, and seven days after the surgery. The patients' headache responses were recorded as lack of headache, minor headache, average headache, and severe headache. The collected data was analyzed using SPSS, version 18. In addition, this clinical trial was registered at the Iranian Registry of Clinical trials database (http://www.irct.ir) with IRCT20200412047041N1.

\section{RESULTS}

In the present study, 280 patients were studied. Their average age was $32.7 \pm 11$ years old; ranging from 18 to 65 . The gender distribution of this study was as follows: 214 men $(86.4 \%)$ and 66 women (13.6\%). From among all the individuals studied, 160 participants $(57.1 \%)$ had no postspinal anesthesia headache, back pain, nausea, and vomiting. However, 120 participants $(42.9 \%)$ showed at least one of these complications. Additional information about the patients participated in this study is given in (Table 1).

The most frequent was related to leg and knee surgery with $126(47.54 \%)$ and the least surgery was related to femoral and hip with $50(18.86 \%)$ and also ankle and foot surgery was 89 (33.58\%).

With regard to age and gender distribution, no significant difference was observed between the two groups studies ( $\mathrm{P}>0.05)$ (Table 2).

Nausea, vomiting, and headache on the first day after surgery in the dexamethasone group (6.4\%) were significantly lower than in the control group (18.6). However, there was no statistically significant difference between the three variables of back pain, headache three days after surgery and headache seven days after surgery in both control and dexamethasone groups $(\mathrm{P}>0.05)$. (Table 3$)$ 
Table 1. Frequency distribution, the complications of spinal anesthesia in the participants of the present study.

\begin{tabular}{|c|c|c|c|}
\hline- & - & Frequency & Percent \\
\hline \multirow{3}{*}{ Nausea and Vomiting } & Lack & 245 & 87.5 \\
& Existence & 35 & 12.5 \\
\cline { 2 - 4 } & Lack & 243 & 86.8 \\
\hline \multirow{3}{*}{ Back ache } & Existence & 37 & 13.2 \\
\cline { 2 - 4 } & Lack & 225 & 80.4 \\
\cline { 2 - 4 } & Light & 34 & 12.1 \\
\cline { 2 - 4 } & Middle & 18 & 6.4 \\
\cline { 2 - 4 } & Severe & 211 & 1.1 \\
\hline \multirow{3}{*}{ Headache First Day } & Lack & 26 & 75.4 \\
\cline { 2 - 4 } & Light & 31 & 9.3 \\
\cline { 2 - 4 } & Middle & 12 & 11.1 \\
\cline { 2 - 4 } & Severe & 274 & 4.3 \\
\hline & Lack & 5 & 97.9 \\
\cline { 2 - 4 } & Light & 1 & 1.8 \\
\hline
\end{tabular}

Table 2. Distribution of gender and age in study groups $(\mathbf{n}=\mathbf{2 8 0})$.

\begin{tabular}{|c|r|r|r|}
\hline- & Dexamethasone & Control & P-value \\
\hline Gender (male: female) & $112: 28$ & $102: 38$ & ${ }^{\mathrm{a}} 0.102$ \\
\hline Age in Year $($ mean \pm Sd) & $31.5 \pm 10.4$ & $33.9 \pm 11.5$ & ${ }^{\mathrm{b}} 0.079$ \\
\hline \multicolumn{3}{|c|}{ a. Fischer's Exact Test ، b. Independent sample t-test } \\
\hline
\end{tabular}

Table 3. Distribution of frequency and percentage frequency of headache on the seventh day after surgery according to study groups.

\begin{tabular}{|c|c|c|c|}
\hline- & $\begin{array}{c}\text { Dexamethasone } \\
\text { N (\%) }\end{array}$ & $\begin{array}{c}\text { Control } \\
\text { N (\%) }\end{array}$ & P.value \\
\hline Nausea and Vomiting & $9(6.4)$ & $26(18.6)$ & $0.002^{*}$ \\
\hline Back Pains & $17(12.1)$ & $20(14.3)$ & $0.362^{*}$ \\
\hline Headache First Day & $21(15)$ & $34(24.3)$ & $0.035^{*}$ \\
\hline Headache Second Day & $35(25)$ & $34(24.3)$ & $0.500^{*}$ \\
\hline Headache Seventh Day & $2(1.4)$ & $4(2.9)$ & $0.342 *$ \\
\hline \multicolumn{3}{|l|}{} \\
\hline \multicolumn{4}{|r}{ * Fischer's Exact Test } \\
\hline
\end{tabular}

\section{DISCUSSION}

Spinal anesthesia is a safe and efficient anesthetic method used in obstetrics and gynecology and orthopedic surgeries [17]. Post-Dural-Puncture Headache as one of the common complications of spinal anesthesia is recognized with the vague and self-limiting beating headaches [6]. Due to the developed medical techniques, the incidence of PDPH has greatly reduced. With respect to the incidence rate of post-spinal anesthesia headache, the previous studies have reported different percentages ranging from 0.2 to 24 percent [18, 19]. Moreover, the positive effects of Dexamethasone on the periodontal ligament stem cells have been confirmed in other studies [20]. In the present study, the effect of intravenous Dexamethasone on post-spinal anesthesia headache was studied on the orthopedic patients of Jiroft Imam Khomeini Hospitals from 2015 to 2016. In some studies, the incidence rate of the post-surgical PDPH has been reported for one-third of the patients [21]. In the present study, the incidence of PDPH was reported to be 24.3 for the patients who did not undergo any intervention; given the findings of the previous studies, its prevalence is quite high. In the present study, the average age of the patients experiencing PDPH was significantly lower than those who did not experience any postsurgical headache. According to some of the previous studies, such as the one conducted by Leibold et al., 1993, PDPH is commonly prevalent among the young adults especially those with the average range of 18-30 [22]. In some of the studies, young women and especially pregnant women were the most likely individuals suffering from PDPH [23]. In the study conducted by Imarengiaye et al., 2006, conducted on 119 spinal anesthesia patients, the incidence rate of PDPH was reported to be 7.22 percent [24]. In the present study, the prevalence of the first day headache among the participants receiving Dexamethasone was significantly $9 \%$ lower than that of the control group that was 24 percent. However, on the third and seven days, no significant difference was observed between the two groups with respect to the headache they experienced. The number of patients reported to have headaches on the third day in the group receiving Dexamethasone increased, and it equaled the number of headache suffering patients who received placebo. This headache reduced to a great deal on the seventh day; in both groups, a number of patients reported the headache. The findings of the present study indicated that PDPH is not a severe complication for spinal anesthesia, and Dexamethasone does not have a remarkable effect on the recovery of the patients' PDPH; this is consistent with the findings of some of the previous studies [25 - 27]. In the study conducted by Manuchehrian et al., 2011, it is claimed that prescribing 8mg of intravenous Dexamethasone as prophylactic can remarkably reduce the incidence rate of post-spinal anesthesia headache in women who had undergone elective caesarean section [28]. However, in the study conducted by Motaghi et al., 2011 on the women candidate for elective caesarean section, the 
findings indicated that prescribing $8 \mathrm{mg}$ of prophylactic Dexamethasone does not have any effect on the incidence rate of the post-spinal anesthesia headache [29]. In the study conducted by Doroudian et al., 2010 [30], conducted on orthopedic patients, the researchers indicated that there was no significant statistical difference between the Dexamethasone group and the placebo group with respect to PDPH incidence. However, the severity of headache was reported to be lower through prescribing intravenous prophylactic Dexamethasone. In the study conducted by Hamzei et al., 2010, through conducting a similar study on the women candidate for caesarean section, they resulted that intravenous Dexamethasone reduces the incidence of PDPH in the first 24 hours and the first week following the spinal anesthesia [26]. In the study conducted by Yousefshahi et al., 2012, it was observed that prophylactic treatment by $8 \mathrm{mg}$ of Dexamethasone not only increases the severity and incidence rate of PDPH, but it also does not have any effect on reduced nausea and vomiting of para-caesarean section surgery [25]. These researchers have recognized prophylactic Dexamethasone as a significant risk factor for creating PDPH. In fact, unlike other studies, the findings of the present study indicated that Dexamethasone affects the reduction of nausea and vomiting of post-spinal anesthesia.

\section{CONCLUSION}

Given the findings of the present study, it seems that the analgesic effect of Dexamethasone in the first 24 hours will lead to the reduction of minor headaches in the patients who had undergone orthopedic surgery through the spinal anesthesia method. However, it does not affect the incidence of more severe headaches. In fact, prescribing $8 \mathrm{mg}$ of prophylactic Dexamethasone after spinal anesthesia does not have a preventive effect on the incidence of PDPH. Reduction of nausea/vomiting and HA in the dexamethasone group is a significant finding, however, that single dose dexamethasone does not prevent later onset, and recommended rather than dismissing the dexamethasone, should consider investigating the efficacy of the repetitive dosing in the future studies.

\section{ETHICS APPROVAL AND CONSENT TO PARTI- CIPATE}

The trial was approved by Jiroft University of Medical Science, Iran. In addition, this clinical trial was registered at the Iranian Registry of Clinical trials database (http://www. irct.ir) with IRCT20200412047041N1.

\section{HUMAN AND ANIMAL RIGHTS}

No animals were used in this research. All human research procedures were followed in accordance with the ethical standards of the committee responsible for human experimentation (institutional and national), and with the Helsinki Declaration of 1975, as revised in 2013.

\section{CONSENT FOR PUBLICATION}

Written informed consent was obtained from all the participants.

\section{AVAILABILITY OF DATA AND MATERIALS}

The data and materials used to support the findings of this study are available from the corresponding author (J.S.) upon reasonable request.

\section{FUNDING}

None.

\section{CONFLICT OF INTEREST}

The authors declare no conflict of interest, financial or otherwise.

\section{ACKNOWLEDGEMENTS}

Declared none.

\section{REFERENCES}

[1] Bryant B, Knights K. Pharmacology for health professionals ebook:. Elsevier Health Sciences 2014.

[2] Miller R, Eriksson L, Fleisher L, Wiener-Kronish J, Cohen N, Young W. Eds Miller's anesthesia e-book. 9th Ed. Elsevier Health Sciences 2014.

[3] Mason L, Smith LA, Edwards J, Moore R, McQuay HJ, Moore AR. Single dose oral naproxen for acute postoperative pain. Cochrane database of systematic reviews 2003 (2). [http://dx.doi.org/10.1002/14651858.CD004234]

[4] Russell IF. A prospective controlled study of continuous spinal analgesia versus repeat epidural analgesia after accidental dural puncture in labour Int J Obstet Anesth 2012; 21(1): 7-16. [http://dx.doi.org/10.1016/j.ijoa.2011.10.005] [PMID: 22153280]

[5] Konrad C, Schüpfer G, Wietlisbach M, Gerber H. Learning manual skills in anesthesiology: Is there a recommended number of cases for anesthetic procedures? Anesth Analg 1998; 86(3): 635-9.

[http://dx.doi.org/10.1213/00000539-199803000-00037] [PMID: 9495429]

[6] Turnbull DK, Shepherd DB. Post-dural puncture headache: Pathogenesis, prevention and treatment. Br J Anaesth 2003; 91(5): 718-29.

[http://dx.doi.org/10.1093/bja/aeg231] [PMID: 14570796]

[7] Sadeghi SE, Rahimiyan M, Razmi R, Abdollahyfard G. Effect of intravenous single dose of aminophylline on prevention of post dural puncture headache in patients who underwent spinal anesthesia: double blind randomized trial study. Majallah-i Danishgah-i Ulum-i Pizishki-i Gurgan 2010; 12(3): 24-8.

[8] Gosch UW, Hueppe M, Hallschmid M, Born J, Schmucker P, Meier T. Post-dural puncture headache in young adults: Comparison of two small-gauge spinal catheters with different needle design. Br J Anaesth 2005; 94(5): 657-61.

[http://dx.doi.org/10.1093/bja/aei100] [PMID: 15722381]

[9] Tavakol K, Ghaffari P, Hassanzadeh A. Study of the effect of dexamethasone and normal saline in reducing headache after spinal anesthesia in cesarean section. Armaghane danesh 2007; 12(3): 87-94.

[10] Olesen J, Bes A, Kunkel R, Lance JW, Nappi G, Pfaffenrath V, et al. The International Classification of Headache Disorders, $3^{\text {rd }}$ edition (beta version). Cephalalgia 2013; 33(9): 629-808.

[http://dx.doi.org/10.1177/0333102413485658] [PMID: 23771276]

[11] Pannullo SC, Reich JB, Krol G, Deck MD, Posner JB. MRI changes in intracranial hypotension. Neurology 1993; 43(5): 919-26. [http://dx.doi.org/10.1212/WNL.43.5.919] [PMID: 8492946]

[12] Júnior V, Teixeira A, Wanderley V, Moraes E, Araujo A. Morphological analysis of neonates of rats treated with dexamethasone in the initial phase of pregnancy. Int J Morphol 2008; 6(3): 523-7.

[13] Moral Turiel M, Rodríguez Simón MO, Sahagún de la Lastra J, Yuste Pascual JA. Treatment of post-dural-puncture headache with intravenous cortisone. Rev Esp Anestesiol Reanim 2002; 49(2): 101-4. [PMID: 12025238]

[14] Neves JF, Vieira VL, Saldanha RM, et al. [Hydrocortisone treatment and prevent post-dural puncture headache: Case reports]. Rev Bras Anestesiol 2005; 55(3): 343-9.

[http://dx.doi.org/10.1590/S0034-70942005000300011] [PMID: 19471839] 
[15] Tavakol K, Ghafari P, Hasanzadeh A. The effectiveness of dexamethasone and normal saline on reducing of post dural puncture headache in cesarean section. Armaghan Danesh J 2007; 12(3): 87-94.

[16] Ghai A, Wadhera R. Adrenocorticotrophic hormone - Is a single dose sufficient for post-dural puncture headache? Acta Anaesthesiol Scand 2007; 51(2): 266.

[http://dx.doi.org/10.1111/j.1399-6576.2006.01226.x] [PMID: 17261154]

[17] Di SC, Rossi M, Casati A, Cocco C, Fanelli G. Spinal anesthesia: An evergreen technique. Acta bio-medica. Atenei Parmensis 2008; 79(1): 9-17.

[18] Greene BAA. A 26 gauge lumbar puncture needle: Its value in the prophylaxis of headache following spinal analgesia for vaginal delivery. Anesthesiology 1950; 11(4): 464-9.

[http://dx.doi.org/10.1097/00000542-195007000-00009] [PMID: 15432952]

[19] Tarrow AB. Solution to spinal headaches. Int Anesthesiol Clin 1963; 1(3): $877-88$.

[http://dx.doi.org/10.1097/00004311-196305000-00034]

[20] Roozegar MA, Mohammadi TM, Havasian MR, et al. In vitro Osteogenic impulse effect of Dexamethasone on periodontal ligament stem cells. Bioinformation 2015; 11(2): 96-100.

[http://dx.doi.org/10.6026/97320630011096] [PMID: 25848170]

[21] Evans RW, Armon C, Frohman EM, Goodin DS. Assessment: prevention of post-lumbar puncture headaches: Report of the therapeutics and technology assessment subcommittee of the american academy of neurology. Neurology 2000; 55(7): 909-14. [http://dx.doi.org/10.1212/WNL.55.7.909] [PMID: 11061243]

[22] Leibold RA, Yealy DM, Coppola M, Cantees KK. Post-dural-puncture headache: Characteristics, management, and prevention. Ann Emerg Med 1993; 22(12): 1863-70.

[http://dx.doi.org/10.1016/S0196-0644(05)80416-0] [PMID: 8239110]

[23] Kuntz KM, Kokmen E, Stevens JC, Miller P, Offord KP, Ho MM. Post-lumbar puncture headaches: Experience in 501 consecutive procedures. Neurology 1992; 42(10): 1884-7. [http://dx.doi.org/10.1212/WNL.42.10.1884] [PMID: 1407567]

[24] Imarengiaye C, Ekwere I. Postdural puncture headache: A crosssectional study of incidence and severity in a new obstetric anaesthesia unit. Afr J Med Med Sci 2006; 35(1): 47-51.

[PMID: 17209327]

[25] Yousefshahi F, Dahmardeh AR, Khajavi M, Najafi A, Khashayar P, Barkhordari K. Effect of dexamethasone on the frequency of postdural puncture headache after spinal anesthesia for cesarean section: A double-blind randomized clinical trial. Acta Neurol Belg 2012; 112(4): 345-50.

[http://dx.doi.org/10.1007/s13760-012-0065-6] [PMID: 22527786]

[26] Hamzei A, Basiri-Moghadam M, Pasban-Noghabi S. Effect of dexamethasone on incidence of headache after spinal anesthesia in cesarean section. A single blind randomized controlled trial. Saudi Med J 2012; 33(9): 948-53.

[PMID: 22964805]

[27] Yang B, Li D-L, Dong P, Zhang X-Y, Zhang L, Yu J-G. Effect of dexamethasone on the incidence of post-dural puncture headache after spinal anesthesia: A randomized, double-blind, placebo-controlled trial and a meta-analysis. Acta Neurol Belg 2015; 115(1): 59-67. [http://dx.doi.org/10.1007/s13760-014-0307-x] [PMID: 24865592]

[28] Manuchehrian N, Arjomandi M, Bakhshaeu M, Hajian P, Alipur N, Farhanchi A. Efficacy of prophylactic intravenous dexamethasone In: Scientific journal of ilam university of medical sciences. 2012; 19: pp. (4)1-11.

[29] Motaghi K, Safari F, Khodabendelou L, Salimi A. Evaluation the efficacy of IV dexamethasone on post puncture headache incidence after cesarian section. Anesthesia \& Pain 2011; 1(4): 34-40.

[30] Doroudian MR, Norouzi M, Esmailie M, Tanhaeivash R. Dexamethasone in preventing post-dural puncture headache: A randomized, double-blind, placebo-controlled trial. Acta Anaesthesiol Belg 2011; 62(3): 143-6. [PMID: 22145255]

(C) 2020 Barkhori et al.

This is an open access article distributed under the terms of the Creative Commons Attribution 4.0 International Public License (CC-BY 4.0), a copy of which is available at: (https://creativecommons.org/licenses/by/4.0/legalcode). This license permits unrestricted use, distribution, and reproduction in any medium, provided the original author and source are credited. 